\title{
Photodynamic therapy in Barrett's esophagus: Results of treatment of 17 patients
}

\author{
Alan A Weiss MD ${ }^{1}$, Holly AR Wiesinger BSc ${ }^{2}$, David Owen MD $^{3}$
}

\begin{abstract}
AA Weiss, HAR Wiesinger, D Owen. Photodynamic therapy in Barrett's esophagus: Results of treatment of 17 patients. Can J Gastroenterol 2006;20(4):261-264.
\end{abstract}

BACKGROUND: Barrett's esophagus (BE) with dysplasia may progress to esophageal adenocarcinoma. Photodynamic therapy is a promising treatment for BE.

OBJECTIVE: To determine if photodynamic therapy is an acceptable alternative to esophagectomy in BE patients with highgrade dysplasia or early adenocarcinoma.

METHODS: Seventeen patients were treated with photodynamic therapy for BE and high-grade dysplasia or early esophageal adenocarcinoma. Patients with residual Barrett's epithelium were treated with supplemental argon plasma coagulation or potassium titanyl phosphate laser. Patients underwent follow-up endoscopy three, six, nine and 12 months post-treatment, then every six to 12 months. Mean follow-up was 21 months.

RESULTS: High-grade dysplasia or early adenocarcinoma was completely eliminated in nine of 15 (60\%) patients. High-grade dysplasia was downgraded in one patient, persisted in one patient and progressed in four patients. Two patients with early esophageal adenocarcinoma were nonresponders. Complications included stricture, sunburn, urticaria, small pleural effusions, esophageal spasm and transient atrial fibrillation. CONCLUSIONS: Photodynamic therapy with supplemental ablation is a good, noninvasive therapy for elimination of highgrade dysplasia and early adenocarcinoma in BE. Failure to eliminate dysplastic epithelium occurred in $40 \%$ of the patients, thereby necessitating careful follow-up.

Key Words: Adenocarcinoma, Barrett's esophagus, Dysplasia, Photodynamic therapy

\section{$\mathrm{B}$} arrett's esophagus (BE) is considered to be the precursor lesion of esophageal adenocarcinoma. Progression of $\mathrm{BE}$ without dysplasia to low-grade dysplasia (LGD) followed by high-grade dysplasia (HGD) is widely accepted $(1,2)$. There is a wide discrepancy among various studies of the natural history of progression from HGD to cancer. The range is anywhere from $16 \%$ during a 7.3 year period (3) to $59 \%$, tabulated from a five-year cumulative esophageal cancer incidence (4). There is a wide interobserver variance in the diagnosis of dysplasia in the setting of BE. Biopsies indefinite for dysplasia and positive for LGD may have morphological features that overlap with reactive epithelial atypia secondary to reflux esophagitis (5).

In recent years, the incidence of esophageal adenocarcinoma has doubled and continues to be the most rapidly rising cancer

\section{Résultats de la thérapie photodynamique chez 17 patients atteints du syndrome de Barrett}

\begin{abstract}
CONTEXTE : Le syndrome de Barrett (SB), accompagné de dysplasie peut évoluer vers le cancer de l'œsophage. La thérapie photodynamique (TPD) est un traitement prometteur du syndrome.

BUT : L'étude visait à déterminer si la TPD constituait une solution de rechange acceptable à l'oesophagectomie chez des patients atteints du SB, accompagné d'une dysplasie de degré élevé de malignité ou d'un début d'adénocarcinome.
\end{abstract}

MÉTHODE : Dix-sept patients atteints du SB, accompagné d'une dysplasie de degré élevé de malignité ou d'un début de cancer de l'œsophage ont été traités par thérapie photodynamique. Les sujets chez qui l'épithélium de Barrett n'était pas complètement disparu ont été soumis à un traitement complémentaire par coagulation au plasma d'argon ou par laser KTP (potassium titanyl phosphate). Enfin, les patients ont subi une endoscopie de contrôle trois, six, neuf et douze mois après le traitement, puis aux six à douze mois. La durée moyenne du suivi a été de 21 mois. RÉSULTATS : Il y a eu disparition complète de la dysplasie de degré élevé de malignité ou du début de cancer de l'œsophage chez 9 patients sur 15 (60\%). La dysplasie a régressé dans un cas, est restée stable dans un autre cas et a évolué dans quatre autres cas. Deux patients qui présentaient un début de cancer de l'œsophage n'ont pas réagi au traitement. Les sténoses, les coups de soleil, l'urticaire, de petits épanchements pluraux, des spasmes de l'œsophage et la fibrillation auriculaire passagère figuraient parmi les complications.

CONCLUSIONS : La thérapie photodynamique, complétée par un traitement ablatif s'est révélée un moyen efficace, non effractif, de destruction de la dysplasie de degré élevé de malignité ou d'un début de cancer de l'œsophage dans les cas de SB. Toutefois, l'absence de disparition complète de l'épithélium dysplasique dans $40 \%$ des cas appelle un suivi étroit.

incidence in the United States (6). In particular, the incidence in American white men has increased by more than $350 \%$ since the mid-1970s (7).

The Canadian National Cancer Institute estimates that new cases of esophageal cancer will reach approximately 1400 cases in 2004, affecting approximately 1000 men and 400 women. Deaths from esophageal cancer in 2004 are estimated to reach 1600 in total. Actual data from 2000 include a total of 1328 new cases and 1392 deaths. Canadian age-standardized incidence rates (1993 to 1997) were 4.2 and 1.3 per 100,000 for men and women, respectively. In comparison, rates in the United States were 5.1 and 1.4 per 100,000 for men and women, respectively (8).

The current practice guidelines (6) for BE require that patients with HGD must be followed carefully. Initially, they

${ }^{1}$ British Columbia Cancer Agency; ${ }^{2}$ University of British Columbia; ${ }^{3}$ Department of Pathology, University of British Columbia, Vancouver,

British Columbia

Correspondence: Dr Alan A Weiss, British Columbia Cancer Agency, 600 West 10th Avenue, Vancouver, British Columbia V5Z 4 E6.

Telephone: 604-877-6000 fax 604-877-0585, e-mail aweiss@bccancer.bc.ca

Received for publication July 6 2005. Accepted November 222005 
require follow-up endoscopies with special attention paid to any mucosal irregularity, along with an intensive biopsy protocol of four-quadrant biopsies every $1 \mathrm{~cm}$ to $2 \mathrm{~cm}$. HGD may be followed by three-month endoscopic surveillance intervals, but most patients with focal or multifocal HGD should be considered for therapeutic intervention. The guidelines do not specifically recommend which intervention should be considered. Esophagectomy has been a gold standard therapy; however, it is associated with a significant morbidity and mortality rate, especially in many patients with advanced age and comorbid conditions $(6,9)$.

Photodynamic therapy (PDT) has a long-standing history in oncology; it was initially used in 1903 as a treatment for skin cancer (10). PDT was first used in 1990 for two patients with $\mathrm{BE}$ and early stage esophageal cancer (9). Three main components are required to photochemically induce cell death: a photosensitizing agent, a light with appropriate wavelength to activate the agent and singlet oxygen to mediate the photodynamic process $(9,10)$. Sodium porfimer is the photosensitizer used for $\mathrm{BE}$; it is a porphyrin derivative that is activated at a wavelength of $630 \mathrm{~nm}$ (9). It is taken up preferentially by actively dividing cells and in areas with leaky vasculature, such as those around tumours. The agent is administered through intravenous injection approximately $48 \mathrm{~h}$ before the light delivery. A laser light source is used to channel light energy into a fibre and then administered endoscopically. Cytotoxicity is achieved by the generation of singlet oxygen and other free radicals when the light-excited sensitizer loses or accepts an electron (10).

Studies showing the effectiveness of porfimer sodium have been published $(11,12)$. Most recently, Overholt et al (11) presented promising long-term results following porfimerPDT. To our knowledge, no Canadian experience has been published. The current paper presents data from 17 patients treated with porfimer sodium-PDT and acid suppressant therapy, followed by argon plasma coagulation (APC) or potassium titanyl phosphate (KTP) laser ablation for the treatment of BE with HGD or early adenocarcinoma.

\section{Patient selection}

\section{PATIENTS AND METHODS}

A total of 17 patients ( 15 men, two women; mean age 74.6 years, range 52 to 92 years) with $\mathrm{BE}$ were treated and followed from May 1999 to July 2004. Patients were carefully selected based on endoscopically visualized Barrett's epithelium with biopsies showing HGD or early stage adenocarcinoma confirmed by a gastrointestinal pathologist. Those with early stage adenocarcinoma were either nonsurgical candidates due to comorbidities, as deemed by the surgeon consultant, or patients who refused surgery. All patients who underwent PDT were included in the present paper.

\section{Treatment}

Following admission to the British Columbia Cancer Agency Vancouver Clinic, patients underwent an intravenous injection of $2 \mathrm{mg} / \mathrm{kg}$ of the photosensitizing agent, porfimer sodium (Photofrin, Axcan Pharma Inc, Canada). Approximately $48 \mathrm{~h}$ after the injection, patients received their first PDT. Under conscious sedation, an Olympus gastrovideoscope (Olympus America Inc, USA) was inserted into the esophagus to localize the segment of BE. Laser light of $630 \mathrm{~nm}$ wavelength was administered using a high-power KTP dye laser (Laserscope, models $824 \mathrm{Nd}$ :YAG/KTP and 600-633, Sigmacon Health Products Corp, Canada), with either a cylindrical diffuser or a windowed esophageal-centring balloon (Wilson-Cook Medical, Cook Inc, Canada). The centring balloon was used for the day 1 treatment. The balloon allowed centring of the cylindrical fibre optic diffuser in the esophageal lumen and flattened the esophageal folds (13). If a centring cylinder was used, it was placed over the wire, positioned in place and inflated. The length of laser fibre was previously determined and then inserted into the centring balloon. The laser fibre was positioned and secured within the centring cylinder. The gastroscope was then positioned above the centring balloon to monitor the position during treatment. PDT was then commenced, giving $630 \mathrm{~nm}$ light at $400 \mathrm{~mW} / \mathrm{cm}$ delivering $130 \mathrm{~J} / \mathrm{cm}$. The maximum window length for each treatment was $7 \mathrm{~cm}$. Patients with $\mathrm{BE}$ longer than $7 \mathrm{~cm}$ were retreated three months later. Small areas of $\mathrm{BE}$ outside the treatment area or any areas of nodularity were pretreated using short diffusers without a centring balloon, delivering $50 \mathrm{~J} / \mathrm{cm}$.

The extent of the initial PDT was examined endoscopically $48 \mathrm{~h}$ later. Any remaining areas of $\mathrm{BE}$ were retreated with a laser fibre without a centring balloon.

Patients were carefully monitored for any complications during and after the procedure. Because cutaneous photosensitivity is a primary side effect of the sodium porfimer, patients were discharged from the hospital with instructions to avoid sunlight for four to six weeks.

\section{Follow-up}

Follow-up endoscopy was performed three months post-PDT to evaluate the result of PDT and to obtain four-quadrant biopsies every $2 \mathrm{~cm}$ over the length of the original Barrett's mucosa. Any small islands of Barrett's epithelium with LGD or HGD, as well as any nodular areas, were treated with APC or KTP laser. Five of the 13 patients with HGD and one with carcinoma in situ underwent additional treatment with APC or KTP. Four patients required retreatment for a residual long segment of Barrett's epithelium. Further follow-up endoscopy was done at six, nine and 12 months. The follow-up interval was then adjusted depending on biopsy results: every three months if HGD persisted, every six months when LGD was present and annually in patients with three consecutive negative biopsies. Patients who progressed to invasive adenocarcinoma were individually evaluated for either radiation therapy or esophagectomy depending on their clinical status and suitability for surgery. All patients were maintained on proton pump inhibitors.

\section{Baseline characteristics}

\section{RESULTS}

Baseline characteristics of patients are presented in Table 1. Of the 17 total patients, 13 had HGD and four had early esophageal adenocarcinoma. The average age of patients with HGD and cancer was 71.6 and 84.5 years, respectively.

\section{Outcomes}

The pretreatment pathological assessment, Barrett's epithelium length and the post-PDT outcomes are presented in Table 2.

HGD patients: Four patients with HGD had short-segment BE, averaging $2.1 \mathrm{~cm}$ and nine patients had long segments, averaging $7.3 \mathrm{~cm}$. After PDT, seven of $13(54 \%)$ patients with HGD were downgraded to no dysplasia and one $(8 \%)$ was downgraded to LGD. One patient remained stable with HGD during both pre- and post-PDT. Four patients (31\%) progressed from HGD 
TABLE 1

Baseline characteristics

\begin{tabular}{lccc}
\hline & HGD & Early CA & Overall \\
\hline $\mathrm{n}$ & 13 & 4 & 17 \\
Male & 12 & 3 & 15 \\
Female & 1 & 1 & 2
\end{tabular}

Age in years (SD) $71.6(10.2) \quad 84.5(5.2) \quad 74.6(10.7)$

CA Early carcinoma (Tis Intramucosal carcinoma; T1a Intramucosal esophageal adenocarcinoma or T1b Submucosal esophageal adenocarcinoma); HGD High-grade dysplasia

to invasive adenocarcinoma. Barrett's mucosa was completely eliminated in four patients (31\%) with HGD and partially eliminated in eight patients (62\%). One patient (8\%) with HGD had no significant change to the Barrett's surface area. One patient with complete elimination of both BE and HGD for 29 months of follow-up died of cardiac causes.

Three patients required an esophagectomy and are well approximately 42, 18 and 16 months following the surgery. The fourth patient who progressed was not a surgical candidate due to coexisting advanced cirrhosis. The pathology from the first patient's esophagectomy showed well to moderately differentiated T1N0 adenocarcinoma in columnar-lined esophagus with HGD. Before surgery, the length of BE had decreased from $9 \mathrm{~cm}$ to $6 \mathrm{~cm}$. The second patient's pathology showed moderately to poorly differentiated adenocarcinoma invading the muscularis propria, with limited columnar metaplasia at the gastroesophageal junction. The third patient's pathology showed highgrade dysplasia with no cancer.

Early adenocarcinoma patients: Two patients had a diagnosis of esophageal carcinoma in situ before PDT. Following PDT, both had elimination of the carcinoma, without any evidence of dysplasia. One patient had complete elimination of her short-segment $\mathrm{BE}$. The other had a long segment of $\mathrm{BE}$ regress to a small area following PDT and APC.

One patient was diagnosed with intramucosal esophageal adenocarcinoma (T1a) in $8 \mathrm{~cm}$ segment of $\mathrm{BE}$ with extensive HGD. He had partial regression of his BE following PDT; however, his infiltrating carcinoma persisted, even after a course of radiation therapy. He was not a surgical candidate and subsequently died of liver disease.

One patient was referred after a course of radiation therapy, which failed to reverse a mass-like nodularity with HGD. He was not considered a good surgical candidate due to his frailty and advanced age of 91 years. Before PDT, his HGD had progressed to submucosal esophageal adenocarcinoma (T1b) in a short segment of BE. His BE surface area regressed partially post-PDT; however he had persistent infiltrating adenocarcinoma and subsequently died.

\section{Follow-up}

The mean follow-up time for all patients treated with PDT was 21 months, with a range of three to 55 months (Table 3).

\section{Complications}

Five patients developed complications either during or after PDT (Table 4). One of the two patients who experienced sunburn also developed hives during the porfimer treatment. Two patients had bilateral pleural effusions; however, one was subclinical and found incidentally upon imaging. One patient developed a stricture 14 months post-PDT, which was thought to be a combination of both tumour progression and past PDT; he subsequently had an esophagectomy. The low rate of symptomatic strictures could be due to the initial treatment area being no more than $7 \mathrm{~cm}$ in length. Atrial fibrillation in another patient converted spontaneously within $24 \mathrm{~h}$.

\section{DISCUSSION}

Previous studies have shown positive results following treatment with porfimer PDT. Most recently, Overholt et al (11) published a five-year follow-up data from patients treated with porfimer PDT supplemented with Nd:YAG laser for small areas of BE. In this study, HGD was eliminated in 94\% of patients. In addition, the length of Barrett's mucosa decreased by a mean of $6.92 \mathrm{~cm}$. Their results demonstrated that only $4.6 \%$ of patients with HGD developed adenocarcinomas during follow-up, showing a marked reduction in the expected incidence of carcinoma (11). Wolfsen et al (12) reviewed 48 PDT patients with BE and HGD $(n=34)$ or superficial cancer $(n=14)$. They saw apparent complete photoablation of Barrett's mucosa and/or superficial neoplasm in 47 of 48 patients. In our patient population, we saw $62 \%$ of patients with HGD downgraded, and we saw a lower number of patients (54\%) with complete regression of Barrett's mucosa. Our complication rate was low in comparison with other studies, with only one patient developing a stricture that was easily treated with dilation. All other complications were either minor or transient.

The four patients who started with HGD and progressed to cancer were not downgraded post-PDT. Three of the four patient's progressed within nine months of PDT; one of the

\section{TABLE 2}

Prephotodynamic therapy (PDT) parameters and post-PDT outcomes of patients

\begin{tabular}{|c|c|c|c|c|c|c|c|c|c|}
\hline & \multirow[b]{4}{*}{$\mathbf{n}$} & \multicolumn{2}{|c|}{ Pre-PDT } & \multirow[b]{3}{*}{ DG } & \multicolumn{3}{|c|}{ Post-PDT } & \multirow{2}{*}{\multicolumn{2}{|c|}{ Disease progression }} \\
\hline & & \multirow{2}{*}{\multicolumn{2}{|c|}{$\begin{array}{l}\text { Length of } \mathrm{BE} \\
\mathrm{n} \text { (average } \mathrm{cm} \text { ) }\end{array}$}} & & \multirow{2}{*}{\multicolumn{3}{|c|}{$\begin{array}{l}\text { Level of BE elimination } \\
\qquad \mathbf{n}(\%)\end{array}$}} & & \\
\hline & & & & & & & & \multicolumn{2}{|c|}{ n (\%) } \\
\hline & & Short $(<3 \mathrm{~cm})$ & Long $(\geq 3 \mathrm{~cm})$ & n (\%) & BE absent & Partial regression & No change & NSC & Surgery \\
\hline HGD & 13 & $4(2.1)$ & $9(7.3)$ & $8(62)$ & $4(31)$ & $8(62)^{*}$ & $1(8)$ & $1(8)$ & $3(23)^{\dagger \ddagger}$ \\
\hline Early CA & $4 \S$ & $2(2.0)$ & $2(7.5)$ & $2(50)$ & $1(25)$ & $3(75)$ & & $2(50)$ & \\
\hline Total & 17 & $6(2.1)$ & $11(7.4)$ & $10(59)$ & $5(29)$ & $11(65)$ & $1(6)$ & $3(18)$ & $3(18)$ \\
\hline
\end{tabular}

${ }^{*} A l l$ patients with partial regression are being actively monitored and treated; ${ }^{\dagger}$ Three patients have had esophagectomy; ${ }^{\star}$ All three patients progressed within nine months of PDT (range three to nine months); §One patient had radiation therapy 23 months before PDT for mass-like nodularity with high-grade dysplasia (HGD); BE Barrett's epithelium; CA Early carcinoma (Tis Intramucosal carcinoma; T1a Intramucosal esophageal adenocarcinoma; T1b Submucosal esophageal adenocarcinoma); DG Downgraded; NSC Nonsurgical candidate 
TABLE 3

Mean follow-up data

\begin{tabular}{lccc}
\hline Initial grade & $\mathbf{n}$ & Mean follow-up (months) & SD (months) \\
\hline HGD & 13 & 21 & 15 \\
Tis & 2 & 31 & 5 \\
T1a & 1 & 15 & 0 \\
T1b & 1 & 7 & 0 \\
All patients & 17 & 21 & 14
\end{tabular}

HGD High-grade dysplasia; T1a Intramucosal adenocarcinoma; T1b Submucosal adenocarcinoma; Tis Intramucosal carcinoma

three was detected at the first follow-up endoscopy three months post-PDT. The fourth patients HGD progression was detected at 34 months-PDT. All patients were treated with proton pump inhibitors and had good responses endoscopically to therapy with PDT; that is, there was a marked inflammatory response to PDT as visualized on endoscopy $48 \mathrm{~h}$ post-PDT. We could not differentiate responders from nonresponders based on endoscopic appearance. This suggested one or a combination of the following possibilities:

- genetic abnormalities were present in some BE cells which made them PDT-resistant;

- the stem cells repopulating the ablated areas were preprogrammed to progress to malignant states; and

- undetected adenocarcinoma was present before PDT.

As demonstrated in our study, some patients may progress to carcinoma after photodynamic and ablative therapies. Before proceeding with PDT and other endoscopic ablative techniques, it is very important to thoroughly discuss surgical therapy with patients. In the present study, all patients were

\section{REFERENCES}

1. Hamilton SR. Pathogenesis of columnar cell lined (Barrett's) esophagus. In: Spechler SJ, Goyal RK, eds. Barrett's Esophagus: Pathophysiology, Diagnosis and Management. New York: Elsevier, 1985:2937.

2. Spechler SJ. Barrett's esophagus and esophageal adenocarcinoma: Pathogenesis, diagnosis, and therapy. Med Clin North Am 2002;86:1423-45.

3. Schnell TG, Sontag SJ, Chejfec G, et al. Long-term nonsurgical management of Barrett's esophagus with high-grade dysplasia. Gastroenterology 2001;120:1607-19.

4. Reid BJ, Levine DS, Longton G, Blount PL, Rabinovitch PS. Predictors of progression to cancer in Barrett's esophagus: Baseline histology and flow cytometry identify low- and high-risk patient subsets. Am J Gastroenterol 2000;95:1669-76.

5. Reid BJ, Haggitt RC, Rubin CE, et al. Observer variation in the diagnosis of dysplasia in Barrett's esophagus. Hum Pathol 1988;19:166-78.

6. Sampliner RE and The Practice Parameters Committee of the American College of Gastroenterology. Updated guidelines for the diagnosis, surveillance, and therapy of Barrett's esophagus. Am J Gastroenterol 2002;97:1888-95.

7. Devesa SS, Blot WJ, Fraumeni J. Changing patterns in the incidence of esophageal and gastric carcinoma in the United States. Cancer 1998;83:2049-53.
TABLE 4

Complications experienced by patients during and after photodynamic therapy

\begin{tabular}{lc}
\hline Type of complication & Patients $(\mathbf{n})$ \\
\hline Minor & 2 \\
Sunburn & 1 \\
Urticaria & $2^{*}$ \\
Pleural effusion & 1 \\
Esophageal spasm & \\
Major & 1 \\
Atrial fibrillation & \\
Stricture & 1 \\
\hline
\end{tabular}

*Pleural effusion in one patient was subclinical and only found incidentally on imaging; ${ }^{\dagger}$ Atrial fibrillation resolved spontaneously within $24 \mathrm{~h}$

offered surgical treatment and were either considered a high risk for surgery or refused surgery as an initial therapy. The three patients who underwent surgery for progressive disease had an excellent outcome following surgery and thus, with careful followup and early recognition of the development of carcinoma, the surgical therapy can be successful. Research is underway to determine methods to identify those patients with higher risk of progression to cancer, including a combination of histopathology molecular markers to risk stratify patients with LGD (4,14-16).

In summary, our results suggest that PDT with supplemental APC or KTP laser is a valuable, noninvasive therapy for Barrett's esophagus with HGD and early adenocarcinoma and is a practical alternative to esophagectomy in carefully selected patients. However, in some patients, HGD persists and may progress to invasive carcinoma; therefore, careful endoscopic surveillance is required.

8. National Cancer Institute of Canada: Canadian Cancer Statistics 2004, Canada,

9. Wang KK, Kim JY. Photodynamic therapy in Barrett's esophagus. Gastrointest Endosc Clin N Am 2003;13:483-9.

10. Pass HI. Photodynamic therapy in oncology: Mechanisms and clinical use. J Natl Cancer Inst 1993;85:443-56.

11. Overholt BF, Panjehpour M, Halberg DL. Photodynamic therapy for Barrett's esophagus with dysplasia and/or early stage carcinoma: Long-term results. Gastrointest Endosc 2003;58:183-8.

12. Wolfsen HC, Woodward TA, Raimondo M. Photodynamic therapy for dysplastic Barrett esophagus and early esophageal adenocarcinoma. Mayo Clin Proc 2002;77:1176-81.

13. Overholt BF, Panjehpour M. Photodynamic therapy techniques for ablation of Barrett's esophagus. Tech Gastrointest Endosc 2000;2:203-8.

14. Reid BJ, Blount PL, and Rabinovitch PS. Biomarkers in Barrett's esophagus. Gastrointest Endosc Clin N Am 2003;13:369-97.

15. Reid BJ, Prevo LJ, Galipeau PC, et al. Predictors of progression in Barrett's esophagus II: Baseline 17p (p53) loss of heterozygosity identifies a patient subset at increased risk for neoplastic progression. Am J Gastroenterol 2001;96:2839-48.

16. Krishnadath KK, Wang KK, Taniguchi, D, et al. Persistent genetic abnormalities in Barrett's esophagus after photodynamic therapy. Gastroenterology 2000;199:624-30. 


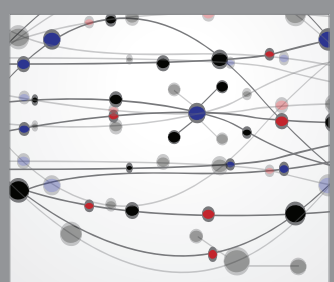

The Scientific World Journal
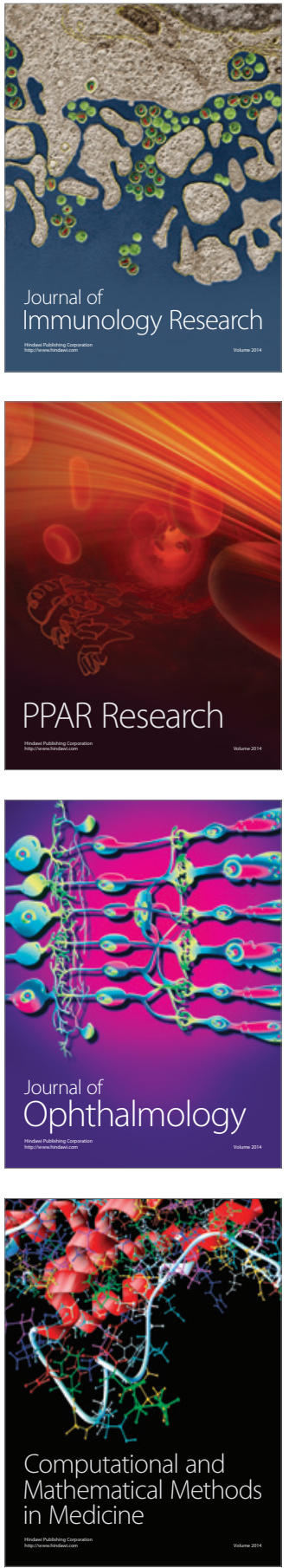

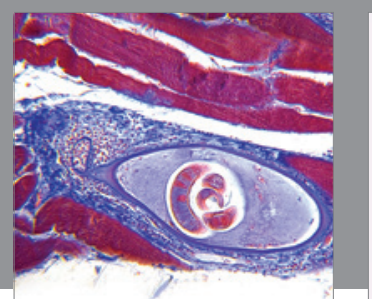

Gastroenterology Research and Practice

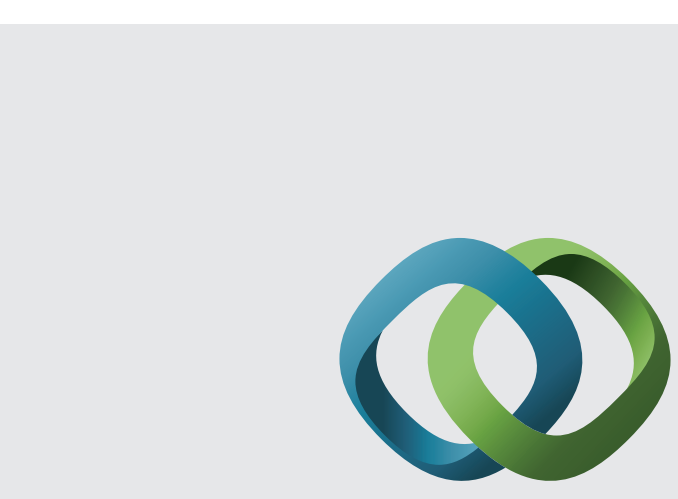

\section{Hindawi}

Submit your manuscripts at

http://www.hindawi.com
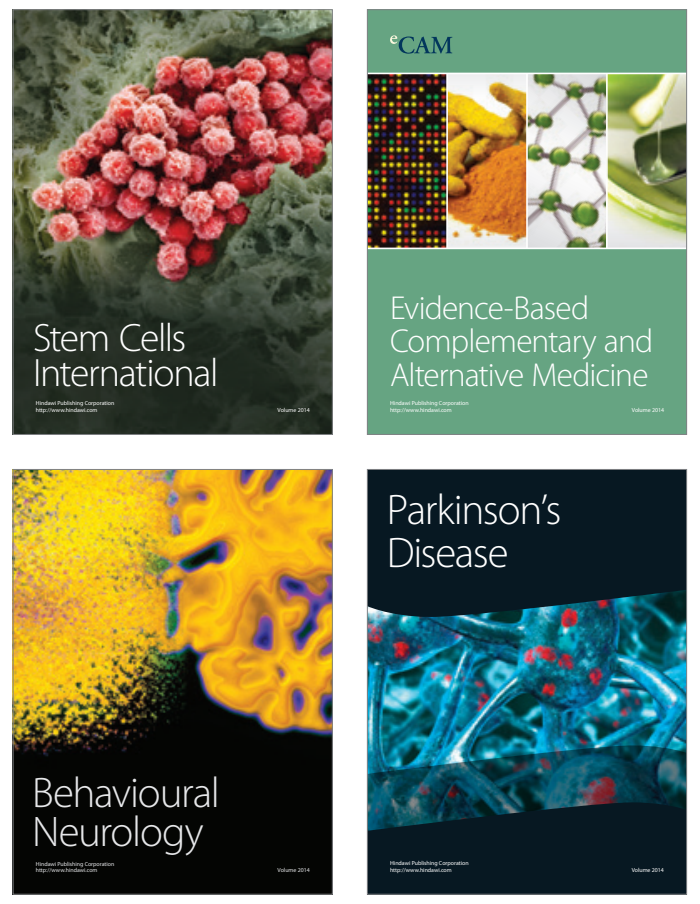
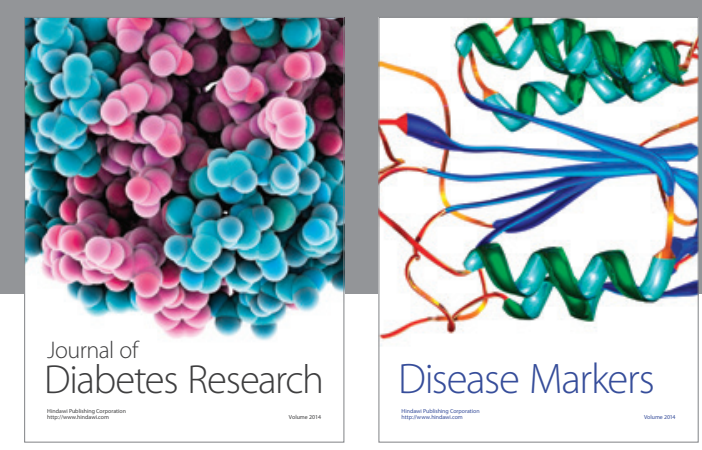

Disease Markers
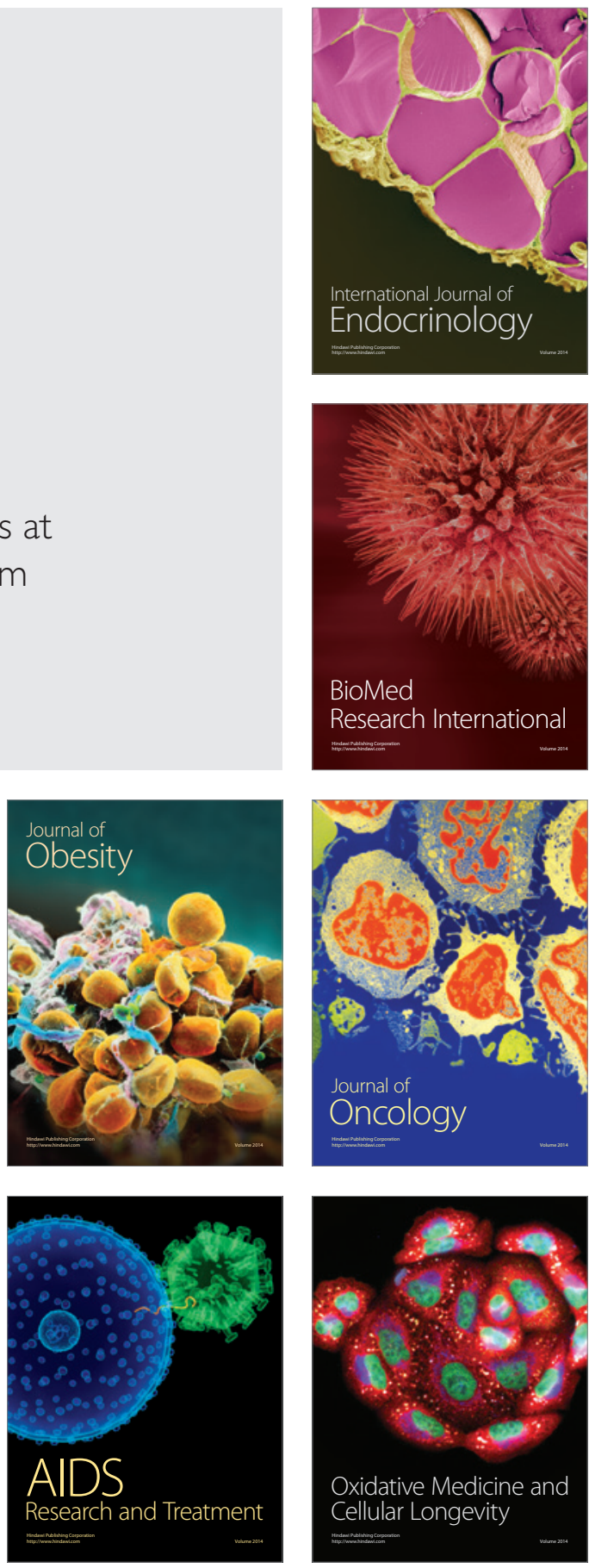